\author{
Military Technical College \\ Kobry El-Kobbah, \\ Cairo, Egypt.
}

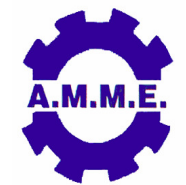

\title{
THE VARIATION OF CYCLONE PERFORMANCE WITH THE CYCLONE HEIGHT USING RANS SIMULATIONS
}

\author{
K. Elsayed ${ }^{*}$ and C. Lacor ${ }^{*}$
}

\begin{abstract}
The effect of the cyclone height (both the barrel and cone) on the performance and flow field pattern has been investigated computationally for six cyclone separators. The results show that the maximum tangential velocity in the cyclone decreases with increasing the cyclone (barrel or cone) height. Increasing the barrel height makes a small change in the axial velocity, whereas increasing the cone height changes it considerably. Increasing the cyclone (barrel or cone) height decreases both the pressure drop and the cut-off diameter. The changes in the performance beyond $h / D$ $=1.8\left(H_{t} / D=4.3\right)$ are small at constant cone height, whereas the performance improvement stops after $h_{d} D=4.0\left(H_{t} D=5.5\right)$ at constant barrel height where $h$ is the barrel height, $h_{c}$ is the cone height, $H_{t}$ is the total cyclone height and $D$ is the barrel diameter. The effect of changing the cone height on the flow pattern and performance is more significant than that of the barrel height.
\end{abstract}

\section{KEY WORDS}

Cyclone Separator, Reynolds Stress Model (RSM), Discrete Phase Modeling (DPM).

* Postdoc Researcher, Department of Mechanical Engineering, Vrije Universiteit Brussel, Pleinlaan 2 -1050 Brussels- Belgium, Email: khairy.elsayed@vub.ac.be.

** Professor, Department of Mechanical Engineering, Vrije Universiteit Brussel, Pleinlaan 2 -1050 Brussels- Belgium, Email: chris.lacor@vub.ac.be. 


\section{INTRODUCTION}

Cyclones are one of the most widely used separators, which rely on centrifugal forces to separate particles from a gas stream. The main advantages are economy, simplicity in construction, and adaptable to a wide range of operating conditions. The flow phenomena in cyclone separators are complex; the flow is highly swirling and fully three-dimensional [1]. This leads to many investigations in order to understand the effect of different geometrical and operating parameters on the performance and hydrodynamics of cyclone separators [2-12].

Numerous studies have been performed for the effect of geometrical parameters on the flow pattern and performance $[1,9,13-16]$ whereas only limited number of studies has been devoted to the effect of the cyclone height. Zhu and Lee [17] have conducted detailed experiments on cyclones of different height and found that the cyclone height can influence considerably the separation efficiency of the cyclones. However they did not provide any information about the flow pattern nor an explanation for the efficiency results. Hoffmann et al. [18] investigated the effect of the cyclone height on the separation efficiency and the pressure drop experimentally and theoretically. They found improvement in cyclone performance with increasing the total height up to 5.5 times cyclone diameters beyond this length the separation efficiency was dramatically reduced. But they did not present any contour plot or velocity profile to support the explanation for the effect of the cyclone height on the performance. Recently Xiang and Lee [19] have repeated the study of Zhu and Lee [17] for the effect of cyclone height via steady three-dimensional simulations using the Reynolds stress turbulence model (RSM). They found that the tangential velocity decreases with increasing the cyclone height, which is responsible for the lower separation efficiency observed in long cyclones. The reason for this behavior however was not analyzed in detail. Moreover, no particle tracking study was presented.

The present study is intended to computationally investigate the effect of increasing cyclone (barrel and cone) height on the pressure drop and cut-off diameter and to obtain more details about the flow field pattern and velocity profiles. A RANS approach with the Reynolds stress turbulence model (RSM) is used.

\section{NUMERICAL SETTINGS}

The Fluent solver has many turbulence models available for simulating turbulent flow. Only the Reynolds stress model (RSM) and large eddy simulation (LES) can capture the main features of the highly complicated swirling flow in cyclone separators [1, 9-11, 19-26]. The Reynolds stress turbulence model has been used in this study to reveal the effect of changing the barrel height on the turbulent flow in the cyclone separator. For the detailed governing equation for both the Reynolds averaged Navier-Stokes equation (RANS) and the discrete phase modelling (DPM) we refer to Elsayed and Lacor [1]. 


\section{Configuration of the Tested Cyclones}

The numerical simulations were performed on four cyclones with different barrel heights (at constant cone height) and three cyclones with different cone heights (at constant barrel height). Figure 1(a) and Table 1 give the cyclones dimensions.

\section{Boundary Conditions}

Table 2 shows the details of the boundary conditions. The air volume flow rate $Q_{i n}=50 \mathrm{~L} / \mathrm{min}$ for all cyclones, air density $1.0 \mathrm{~kg} / \mathrm{m}^{3}$ and dynamic viscosity of $2.11 \mathrm{E}-5$ $\mathrm{Pa}$ s. The turbulent intensity equals $5 \%$ and characteristic length equals 0.07 times the inlet width $[1,21]$.

\section{Selection of the Numerical Schemes}

The following numerical schemes have been used in the current simulations. The QUICK scheme for momentum discretization, the Presto scheme for pressure interpolation. The SIMPLEC algorithm for pressure velocity coupling, the second order upwind scheme for turbulent kinetic energy and the first order upwind for the Reynolds stress [1]. The simulations have been performed on 8 nodes CPU Opteron 64 Linux cluster using FLUENT 6.3.26 finite volume commercial solver. All simulations have been converged with the selected time step of $1 \mathrm{E}-4 \mathrm{~s}$ and the mentioned numerical settings.

\section{Grid Independency Study}

A grid independency study has been performed for the tested cyclones. Three different grids have been tested for each cyclone, to be sure that the obtained results are mesh independent. For example, meshes with respectively 490164, 714029 and 1174029 cells have been used for cyclone B2. The computational results on the three grids are presented in Table 3. As can be seen the maximum difference between the results is less than $5 \%$, so the results on the 490164 cells grid can already considered as sufficiently accurate. However, for excluding any uncertainty, computations have been performed using the 714029 cells grid, where the total number of grid points was not that critical with respect to the computation overhead $[1,27]$. Figure 1(b) shows the surface grid of cyclone C1(B2) used in this study. Table 4 gives the total number of computational cells used for each cyclone after the grid independency study. The hexahedral computational grids were generated using the GAMBIT grid generator.

\section{VALIDATION OF THE NUMERICAL MODEL}

To validate the obtained results, the present simulations are compared with the measurements obtained from Hoekstra [21]. Figure 2 shows that the RSM simulation matches the experimental velocity profile with underestimation of the maximum tangential velocity, and overestimation of the axial velocity at the central region. Considering the complexity of the turbulent swirling flow in the cyclones, the agreement between the simulations and measurements is considered to be quite 
acceptable. A comparison of calculated Euler number (the dimensionless pressure drop based on both, the static $\left(E u_{S}\right)$ and total pressure $\left.\left(E u_{T}\right)\right)$, Stokes number (the dimensionless cut-off diameter (at particle density of $2740 \mathrm{~kg} / \mathrm{m}^{3}$ ) ) with the experimental data [21], is shown in Table 5. Table 5 indicates very small deviations from the experimental values. Consequently, the numerical model employed in this study can be used to analyze the gas flow field and performance of the cyclone separator.

\section{RESULTS}

The flow velocity can be decomposed into three components. The tangential and the axial velocity components are the major velocity components in comparison with the radial velocity component. Xiang and Lee [19] stated that the tangential velocity is the dominant gas velocity in gas cyclones, which results in the centrifugal force for particle separation. The axial component is responsible for the two flow streams (downward and upward).

\section{The Variation of the Velocity and Static Pressure Profiles in the Axial Direction}

Figures 3 - 5 present the radial profiles of the time-averaged tangential and axial velocity and static pressure at nine axial stations (cf. Table 6). As expected, the tangential velocity profiles exhibit the so-called Rankine vortex, which consists of two parts, an outer free vortex and an inner solid rotation in the center (Fig. 3). The tangential velocity distribution in the inner region is rather similar at different sections for the same cyclone. In the outer region, due to the sharp drop in velocity magnitude in the near wall region, the distribution is different but the maximum tangential velocity is similar at all sections for the same cyclone. The axial velocity profiles at nine different stations are shown in Fig. 4. All cyclones show the inverted W profile but the central dip decreases with increasing the barrel (or cone) height (Except at the cyclone bottom for cyclones $\mathrm{C} 2$ and $\mathrm{C} 3$, where the axial velocity shows an inverted $\mathrm{V}$ profile). The radial profiles of the time-averaged static pressure are given in Fig. 5. Like for the tangential velocity, the axial variations of static pressure are very small for the same cyclone. The variations become negligible with increasing barrel (or cone) height. Furthermore, the maximum value of the static pressure decreases when the barrel height is increased.

\section{The Effect of Cyclone Height on the Tangential and Axial Velocity and the Static Pressure Profiles}

The tangential and axial velocity profiles at section S6 (as a representative for the other sections, because the axial variations in the flow variables are small) for the six cyclones are compared in Fig. 6 . The variation of axial velocity with changing barrel height is limited close to the wall especially in the cylindrical part. In the central region the change in axial velocity profile is more pronounced with the dip in axial velocity decreasing with increasing the barrel height. This is the result of the flatting of the pressure distribution results in a smaller pressure force. This may explain also the change of the axial velocity from cyclones B1 to B4. Increasing the cyclone barrel height decreases the maximum tangential velocity. Cyclone B1 has the maximum tangential velocity in comparison with the other cyclones. The effect of increasing the 
barrel height on the maximum tangential velocity is limited. The variation of axial velocity in the three $\mathrm{C}$ cyclones is limited close to the wall with changing the cone height. The axial velocity profiles are very similar except at the central region due to change in the axial velocity profile. Increasing the cyclone cone height decreases the maximum tangential velocity. Cyclone $\mathrm{C} 1$ has the maximum tangential velocity in comparison with the two other cyclones (C2 and C3). From the comparison between the radial profiles of the four $B$ cyclones, the minimum pressure at the cyclone center is almost the same for all cyclones (B1 - B4). The slope of the static pressure radial profile becomes more flat with increasing the barrel height. The minimum pressure at the cyclone center is almost the same for all $\mathrm{C}$ cyclones. The static pressure radial profiles of cyclones C2 and C3 are very close. Increasing the cyclone height (either barrel or cone) decreases the pressure drop, the maximum tangential velocity (vortex strength) and the dip in the axial velocity profile. The effect of increasing the cone height on the axial velocity profile is predominant with respect to the barrel height.

\section{Physical Interpretations for the Effect of Cyclone Cone Height on the Axial Velocity Profile}

The swirling motion of the gas generates a strong radial pressure gradient, the pressure being low in the centre of the vortex and high at the periphery. As the strongly swirling gas enters the confines of the vortex finder on its way out of the cyclone, the swirl is attenuated through friction with the wall. This means that further up the vortex finder the pressure in the centre is higher than at the exit of the separation space: a reverse pressure gradient is present [29] as is clear from Fig.6. This drives an axial flow with dip in the centre of the vortex finder (inverted $W$ profile); this core flow prevails throughout the entire separation space of the cyclone in spite of the attenuation of swirl in the conical part of the cyclone. With increasing the cone height the pressure distribution becomes more flat consequently the pressure force cause the dip in the axial velocity at the centerline becomes less and less. That may explain also the change of the axial velocity from cyclones $\mathrm{C} 1$ to $\mathrm{C} 3$, Figs. 6, 7.

\section{The effect of cyclone height on the flow pattern}

Figure 7 shows the contour plots of the time-averaged static pressure, tangential and axial velocity for cyclones $\mathrm{C} 1-\mathrm{C} 3$. The time-averaged static pressure decreases radially from wall to center. A negative pressure zone appears in the forced vortex region (central region) due to high swirling velocity. The pressure gradient is largest along the radial direction, whereas the gradient in axial direction is very limited. The cyclonic flow is not symmetrical as is clear from the shape of the low-pressure zone at the cyclone center (twisted cylinder). Two vortical motions are exist one moving down (outer vortex) and the other moving up (inner vortex). The highest value of the static pressure decreases with increasing the cone height. The tangential velocity pattern is very similar for all cyclones (Rankine profile). The highest value decreases with increasing the cone height but the differences between cyclones C2 and C3 are small, so that better collection efficiency can be expected when decreasing the cone height. 
Figure 8 shows the contour plots of the time-averaged static pressure, tangential and axial velocity for cyclones B1-B4. The highest value of the static pressure decreases with increasing the barrel height. The tangential velocity pattern is very similar for all cyclones (Rankine profile). The highest value decreases with increasing the barrel height but the differences between the four cyclones are small. The axial velocity patterns for the four cyclones have the shape of an inverted $\mathrm{W}$ profile.

\section{The effect of cyclone height on the performance}

In order to estimate the effect of cyclone height on the performance parameters, the Euler numbers (the dimensionless pressure drop) have been calculated. A discrete phase modeling (DPM) study has been performed by injecting $10^{4}$ particles from the inlet surface with a particle density of $860 \mathrm{~kg} / \mathrm{m} 3$ and with a particle size ranging from 0.025 till 5 micron.

Figure 9 and Table 7 show a sharp decrease of the Euler number with increasing the barrel height until $h / D>1.8\left(H_{t} / D>4.3\right)$ and a gradual decrease beyond. This behavior can be explained as follows. The pressure drop in the cyclone is composed of three main contributions [1]: (1) the pressure drop at the inlet section. (2) the pressure drop in the cyclone body due to swirling motion and due to wall friction, this contribution may increase with increasing the cyclone height as the wall friction will increase due to friction with a larger wall surface, or decreases as the vortex strength will decrease because the maximum tangential velocity decreases. (3) the main contribution to the cyclone pressure drop is the energy loss in the exit tube, which mainly depends on the maximum tangential velocity in the cyclone. As is clear from Fig. 6 the maximum tangential velocity decreases with increasing cyclone barrel height. As the inlet section is the same in all cyclones, the pressure drop in the inlet section does not vary with increasing barrel height. The sharp decrease of the Euler number between cyclones B1 and B2 is due to the decrease in the pressure drop as a result of the decrease in the maximum tangential velocity. There are two competing contributions: increase of the pressure drop due to friction and decrease of the pressure drop due to reduction in the vortex strength. At the beginning the wall friction effect is small in comparison with the effect of vortex strength, and for longer cyclones this effect become larger (but still less than that of vortex strength decay). That also that explain the small variation of the Euler number with the barrel height for $h / D>1.8$, that is also clear from Fig. 6 where the maximum tangential velocity of cyclones B3 and B4 are very close.

The behavior of the Stokes number curve as a function of barrel height is quite reasonable with increasing barrel height (separation space), the possibility of particles to be captured increases due to the increased cyclone space. However, the vortex strength decreased with a small amount due to the reduction of the maximum tangential velocity, the main contribution here is the collecting surface. The Stokes number curve becomes nearly flat between cyclones B3 and B4 due to the small changes in both the axial and the tangential velocity profile between the two cyclones. Both Ramachandran [30] and lozia [31] models agree with the CFD results in the trend of decreasing both the Euler number and Stokes number with increasing barrel height, but differ in slope and values. 


\section{The effect of cyclone cone height on the performance}

Figure 10 and Table 8 show a sharp decrease of both the Euler number and the Stokes number with increasing the cone height until $h_{d} D=3.3$ and a gradual decrease when $3.3>h_{d} h>4.0$. This behavior can be explained as follows. As the inlet section is the same in all cyclones, the pressure drop in the inlet section may not vary with increasing the cone height. The sharp decrease in the Euler number between cyclones $\mathrm{C} 1$ and $\mathrm{C} 2$ is due to the huge decrease in the pressure drop in the cyclone body due to the drop in the maximum tangential velocity (the decay of the vortex strength). There are two competing contributions, increase of the pressure drop due to friction and decrease of the pressure drop due to reduction in the vortex strength. At the beginning, the decay in the pressure drop due to the decay of the vortex strength overrides the effect of increasing the pressure drop due to wall friction for longer cyclones. That also explains the small variation of the Euler number with the cone height for $h_{c}>4.0$, which is also clear from Fig. 6 where the maximum tangential velocity of cyclones $\mathrm{C} 2$ and $\mathrm{C} 3$ are very close.

The trend of decreasing Stokes number with increasing cone height is quite reasonable, as more separation space exists, and the possibility of particles to be captured increases. Although, the vortex strength decreased with a small amount due to the reduction in the maximum tangential velocity- we estimate that the main contribution to the collection efficiency comes from the increased collecting surface with increasing the cone height. The reason of nearly constant Stokes number after $H_{t} / D=5.5$ is the change in the axial velocity profile. Figure 6 shows a higher kinetic energy of the flow at the cyclone bottom for cyclone $\mathrm{C} 3$, that will enhance reentrainment of some of the captured particles to escape with the upward flow, consequently low collection efficiency and higher cut-off diameter (Stokes number). Because, the differences between the axial and tangential velocity profile between cyclones $\mathrm{C} 2$ and $\mathrm{C} 3$ are limited.

\section{The cone height versus the barrel height}

- Increasing the cyclone total height (either by increasing the cone or the barrel height) will decrease the maximum tangential velocity.

- The effect of cone height on the axial velocity profile is much larger than that of the barrel height.

- Both the Euler and the Stokes numbers decrease with increasing the total height either by increasing the barrel or cone height. The effect of changing the cone height is more important than that of changing the barrel height (cf. Table 7, 8 and Fig. 12).

- The effect of increasing the ratio of cone to barrel height $\mathrm{hc} / \mathrm{h}$ on the cyclone performance depends on the dependent variable. If hc/h increases at constant cone height, the Euler number increases linearly with decreasing the barrel height. If $\mathrm{hc} / \mathrm{h}$ increases at constant barrel height, the Euler number decreases with increasing the cone height.

- The effect of changing $\mathrm{hc} / \mathrm{h}$ at constant cone height has a negligible effect on the Stokes number.

- Increasing hc/h at constant barrel height decreases the Stokes number. This effect becomes negligible for $\mathrm{hc} / \mathrm{h}>2.75$ (Fig. 12). This behavior can be explained by inspecting the variation of the time-averaged static pressure, 
tangential and axial velocity profiles with cone and barrel height, Fig. 13. As is clear from Fig. 13 the differences between the maximum tangential velocities in cyclones $\mathrm{C} 2$ and $\mathrm{C} 3$ are negligible. Furthermore, the effect of the cone height on the flow field is more significant than that of the barrel height.

\section{CONCLUSIONS}

Six cyclones of different barrel and cone height have been simulated using the Reynolds stress model (RSM), to study the effect of cyclone height on the performance and flow pattern. The following conclusions have been obtained.

- The maximum tangential velocity in the cyclone decreases with increasing the cyclone (barrel or cone) height.

- No acceleration occurs in the cyclone space (the maximum tangential velocity nearly constant throughout the same cyclone).

- Increasing the barrel height, makes a small change in the axial velocity.

- Increasing the cyclone barrel height decreases the pressure drop and the cutoff diameter. But the changes in the performance beyond $h / D=1.8$ are small.

- Increasing the cone height makes a considerable change in the axial velocity.

- Both the pressure drop and the cut-off diameter decrease with increasing the cyclone cone height. The performance improvement stops after $h_{C} D=4.0$ $\left(H_{t} / D=5.5\right)$.

- The effect of changing the barrel height is less significant on the performance and the flow pattern in comparison with the effect of the cone height.

As a recommendation of future work, the same study is to be performed but at different flow rates and different particle densities. Also the effect of increasing the cyclone height on natural vortex length and precessing vortex core needs more investigation.

\section{REFERENCES}

[1] K. Elsayed, C. Lacor, The effect of cyclone inlet dimensions on the flow pattern and performance, Applied Mathematical Modeling, 35 (4) (2011) 1952-1968.

[2] A. J. Hoekstra, J. J. Derksen, H. E. A. Van Den Akker, An experimental and numerical study of turbulent swirling flow in gas cyclones, Chemical Engineering Science 54 (1999) 2055-2065.

[3] G. Solero, A. Coghe, Experimental fluid dynamic characterization of a cyclone chamber, Experimental Thermal and Fluid Science 27 (2002) 87-96.

[4] L. Y. Hu, L. X. Zhou, J. Zhang, M. X. Shi, Studies on strongly swirling flows in the full space of a volute cyclone separator, AIChE J., 51 (3) (2005) 740-749.

[5] P. A. Yazdabadi, A. J. Grifflths, N. Syred, Characterization of the PVC phenomena in the exhaust of a cyclone dust separator, Experiments in Fluids 17 (1994) 84-95. 
[6] T. O'Doherty, A. J. Griffiths, N. Syred, P. J. Bowen, W. Fick, Experimental analysis of rotating instabilities in swirling and cyclonic flows, Developments in Chemical Engineering and Mineral Processing 7 (1999) 245-267.

[7] B. Zhang, S. Hui, Numerical simulation and PIV study of the turbulent flow in a cyclonic separator, in: International Conference on Power Engineering, Hangzhou, China, 2007.

[8] W. D. Griffiths, F. Boysan, Computational fluid dynamics (CFD) and empirical modelling of the performance of a number of cyclone samplers, Journal of Aerosol Science 27 (2) (1996) 281-304.

[9] J. Gimbun, T. G. Chuah, T. S. Y. Choong, A. Fakhru'l-Razi, A CFD study on the prediction of cyclone collection efficiency, International Journal for Computational Methods in Engineering Science and Mechanics 6 (3) (2005) $161-168$.

[10] J. Gimbun, T. Chuah, A. Fakhru'l-Razi, T. S. Y. Choong, The influence of temperature and inlet velocity on cyclone pressure drop: a CFD study, Chemical Engineering and Processing 44 (1) (2005) 7-12.

[11] B. Zhao, Y. Su, J. Zhang, Simulation of gas flow pattern and separation efficiency in cyclone with conventional single and spiral double inlet configuration, Chemical Engineering Research and Design 84 (2006) 11581165.

[12] K. Elsayed, C. Lacor, The effect of cyclone height on the flow pattern and performance using LES, in: Tenth International Congress of Fluid Dynamics (ICFD10), ASME, Egypt, ICFD10-EG-3003, Ain Soukhna, Red Sea, Egypt, 2010.

[13] F. Boysan, B. C. R. Ewan, J. Swithenbank, W. H. Ayers, Experimental and theoretical studies of cyclone separator aerodynamics, IChemE Symp Series 69 (1983) $305-320$.

[14] R. Xiang, S. H. Park, K. W. Lee, Effects of cone dimension on cyclone performance., Journal of Aerosol Science 32 (4) (2001) 549-561.

[15] K. S. Lim, H. S. Kim, K. W. Lee, Characteristics of the collection efficiency for a cyclone with different vortex finder shapes, Journal of Aerosol Science 35 (6) (2004) 743-754.

[16] A. Raoufi, M. Shams, M. Farzaneh, R. Ebrahimi, Numerical simulation and optimization of fluid flow in cyclone vortex finder, Chemical Engineering and Processing 47 (2008) 128-137.

[17] Y. Zhu, K. W. Lee, Experimental study on small cyclones operating at high flow rates, Journal of Aerosol Science 30 (1999) 1303-1315.

[18] A. C. Hoffmann, M. de Groot, W. Peng, H. W. A. Dries, J. Kater, Advantages and risks in increasing cyclone separator length, AIChE Journal 47 (11) (2001) 2452-2460.

[19] R. B. Xiang, K. W. Lee, Numerical study of flow field in cyclones of different height, Chemical Engineering and Processing 44 (2005) 877-883.

[20] M. D. Slack, R. O. Prasad, A. Bakker, F. Boysan, Advances in cyclone modeling using unstructured grids, Trans IChemE. 78 Part A, (2000).

[21] A. J. Hoekstra, Gas flow field and collection efficiency of cyclone separators, Ph.D. thesis, Technical University Delft (2000).

[22] F. Kaya, I. Karagoz, Performance analysis of numerical schemes in highly swirling turbulent flows in cyclones, Current Science 94 (10) (2008) 1273 1278. 
[23] K. Elsayed, C. Lacor, Optimization of the cyclone separator geometry for minimum pressure drop using mathematical models and CFD simulations, Chemical Engineering Science 65 (22) (2010) 6048-6058.

[24] S. Bernardo, M. Mori, A. Peres, R. Dionisio, 3-D computational fluid dynamics for gas and gas-particle flows in a cyclone with different inlet section angles, Powder Technology 162 (3) (2006) $190-200$.

[25] T. Chuah, J. Gimbun, T. S. Choong, A CFD study of the effect of cone dimensions on sampling aerocyclones performance and hydrodynamics, Powder Technology 162 (2006) $126-132$.

[26] J. Gimbun, T. Chuah, T. Choong, Y. Fakhru'l-Razi, Prediction of the effects of cone tip diameter on the cyclone performance, Aerosol Science and Technology 36 (2005) 1056-1065.

[27] A. Benim, K. Ozkan, M. Cagan, D. Gunes, Computational investigation of turbulent jet impinging onto rotating disk, International Journal of Numerical Methods for Heat and Fluid Flow 17 (3) (2007) $284-301$.

[28] J. J. Derksen, S. Sundaresan, H. E. A. van den Akker, Simulation of massloading effects in gas-solid cyclone separators, Powder Technology 163 (2006) 59-68.

[29] A. Hoffmann, M. De Groot, A. Hospers, The effect of the dust collection system on the flow pattern and separation efficiency of a gas cyclone, The Canadian Journal of Chemical Engineering 74 (1996) 464-470.

[30] G. Ramachandran, D. Leith, J. Dirgo, H. Feldman, Cyclone optimization based on a new empirical model for pressure drop, Aerosol Science and Technology 15 (1991) 135-148.

[31] D. L. Iozia, D. Leith, Effect of cyclone dimensions on gas flow pattern and collection efficiency, Aerosol Science and Technology 10 (3) (1989) 491-500.

Table 1: The geometrical dimensions of the tested cyclones

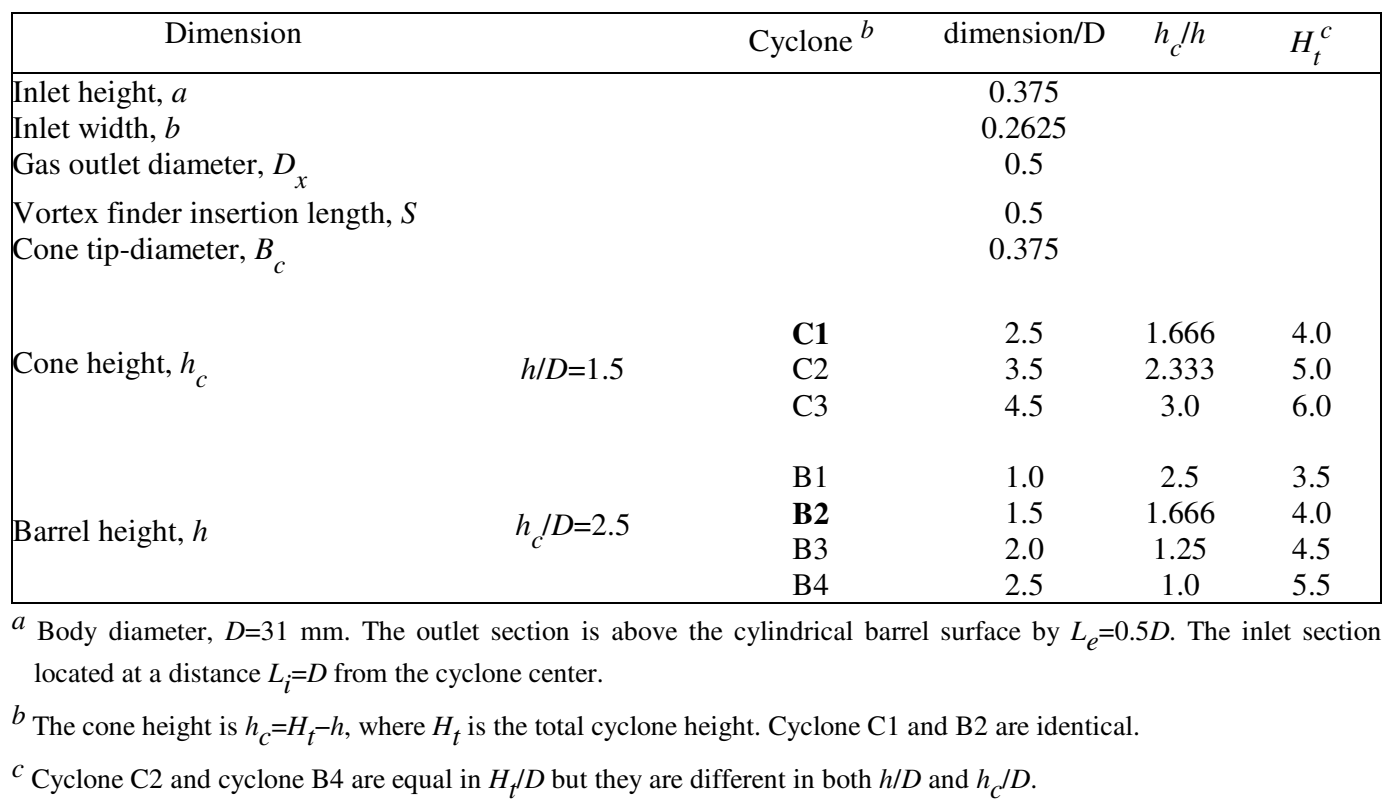

Table 2: The boundary conditions

\begin{tabular}{lcccc}
\hline Boundary & Inlet & Outlet & Cone tip & Other surfaces \\
\hline Condition & Velocity inlet & Outflow & Wall (no-slip) & Wall (no-slip) \\
\hline
\end{tabular}


Table 3: The details of the grid independence study for cyclone C1 (B2)

\begin{tabular}{|lccc|}
\hline \multirow{2}{*}{ Number of cells } & $\mathbf{E u}_{S}{ }^{a}$ & $\mathbf{E u}_{T}$ & Stk $_{50} \mathbf{x}^{3} 0^{3 b}$ \\
\hline 490164 & (based on the static pressure drop) & (based on the total pressure drop) & \\
\hline 714029 & 3.475 & 4.231 & 1.188 \\
1174029 & 3.654 & 4.409 & 1.2 \\
\% difference $^{c}$ & 3.573 & 4.328 & 1.224 \\
\hline
\end{tabular}

$a$ Euler number is the dimensionless pressure drop $E u=\Delta P /\left(\frac{1}{2} \rho V_{i n}^{2}\right)$ where $\Delta P$ is the static pressure drop, $\rho$ is the gas density, $V_{\text {in }}$ is the gas inlet velocity.

$b$ The Stokes number based on the cut-off diameter; $S t k_{50}=\rho_{p}{ }_{50}^{2} V_{i n} /(18 \mu D)$ [28]. It is the ratio between the particle relaxation time; $\rho_{p} x_{50}^{2} /(18 \mu)$ ) and the gas flow integral time scale; $D / V_{\text {in }}$ where $\rho_{p}$ is the particle density $=860 \mathrm{~kg} / \mathrm{m}^{3}$ ,$\mu$ is the gas viscosity.

${ }^{c}$ The percentage difference between the coarsest and finest grid.

Table 4: The details of the tested cyclones $^{a}$

\begin{tabular}{lcccccc}
\hline Cyclone & B1 & B2 (C1) & B3 & B4 & C2 & C3 \\
\hline Number of cells & 688170 & 714029 & 712183 & 786865 & 770556 & 820362 \\
\hline
\end{tabular}

$a$ The total number of hexahedral cells after the grid independency study

Table 5: Validation of the computational pressure drop and cut-off diameter

\begin{tabular}{lccc}
\hline Approach & $\mathbf{E u}_{S}$ & $\mathbf{E u}_{T}$ & $\mathbf{S t k}_{50} \mathbf{x} 0^{3}$ \\
\hline Experimental [21] & 6.0 & 6.259 & 0.349 \\
CFD & 6.18 & 6.439 & 0.325 \\
\% error & 3 & 2.8 & 6.87 \\
\hline
\end{tabular}

Table 6: The position of different plotting sections

\begin{tabular}{lccccccccc}
\hline Section & S1 & S2 & S3 & S4 & S5 & S6 & S7 & S8 & S9 \\
\hline$Z / D^{a}$ & 2.75 & 2.5 & 2.25 & 2 & 1.75 & 1.5 & 1.25 & 1.0 & 0.75 \\
\hline$a Z$
\end{tabular}

$a_{\mathrm{Z}}$ measured from the inlet section top (cf. Fig. 1(a)).

Table 7: The Euler numbers and Stokes numbers for cyclones B1-B4

\begin{tabular}{lcccc}
\hline Cyclone & B1 & B2 & B3 & B4 \\
\hline$h / D$ & 1.0 & 1.5 & 2.0 & 2.5 \\
$h_{c} / h$ & 2.5 & 1.666 & 1.25 & 1.0 \\
$H_{t} / D$ & 3.5 & 4 & 4.5 & 5.0 \\
\hline $\mathbf{E u}$ & 4.39 & 3.654 & 3.33 & 3.09 \\
$\mathbf{E u}($ Ramachandran model [30]) & 5.71 & 4.77 & 4.17 & 3.73 \\
Stk $_{50} \times 10^{3}$ & 1.32 & 1.2 & 1.01 & 0.95 \\
Stk $_{50} \times 10^{3}$ (Iozia model [31]) & 1.94 & 1.82 & 1.72 & 1.64 \\
\hline
\end{tabular}


Table 8: The Euler numbers and Stokes numbers for cyclones C1-C3

\begin{tabular}{lccc}
\hline Cyclone & C1 & C2 & C3 \\
\hline$h_{c} / h$ & 1.666 & 2.333 & 3.0 \\
$h_{c} / D$ & 2.5 & 3.5 & 4.5 \\
$H_{t} / D$ & 4 & 5 & 6 \\
$\mathbf{E u}$ & 3.654 & 2.749 & 2.584 \\
$\mathbf{S t k}_{50} \times 10^{3}$ & 1.2 & 0.465 & 0.315 \\
\hline
\end{tabular}

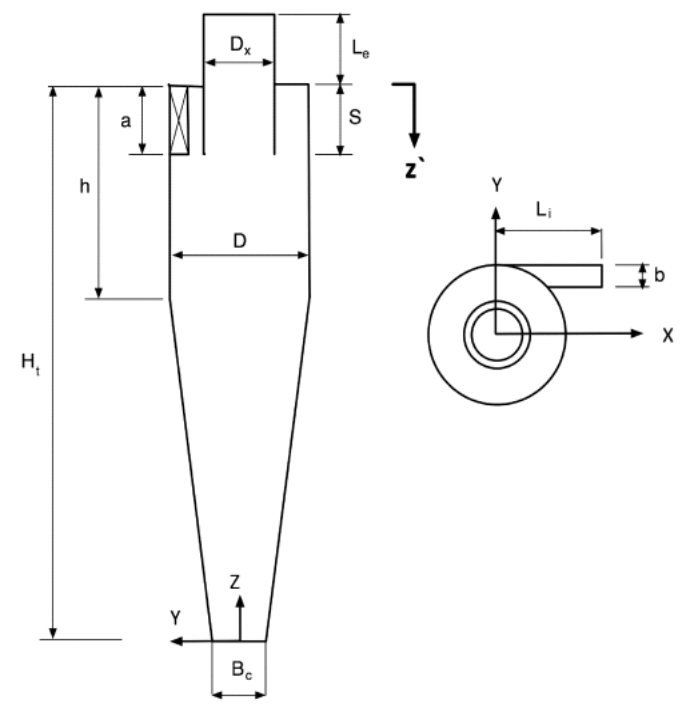

(a) The cyclone geometry

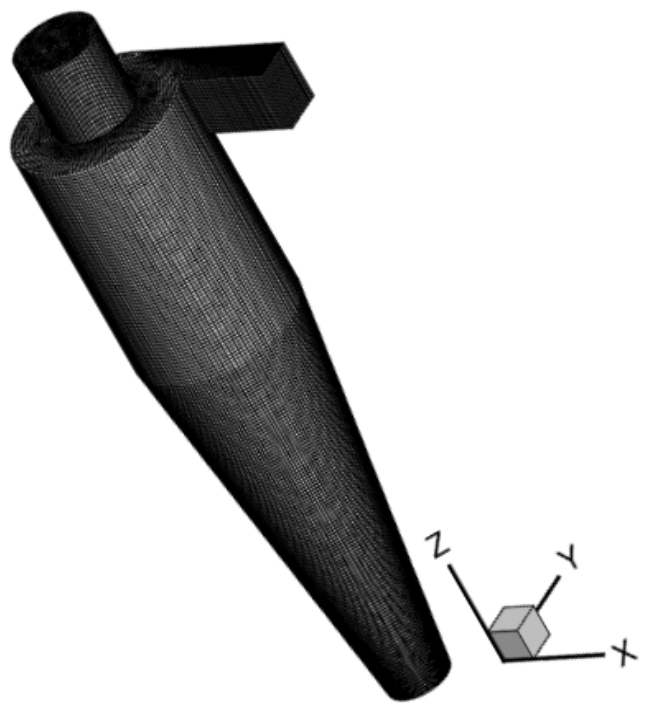

(b) The surface mesh for cyclone C1 (B2)

Fig. 1. Schematic diagram for the cyclone separator
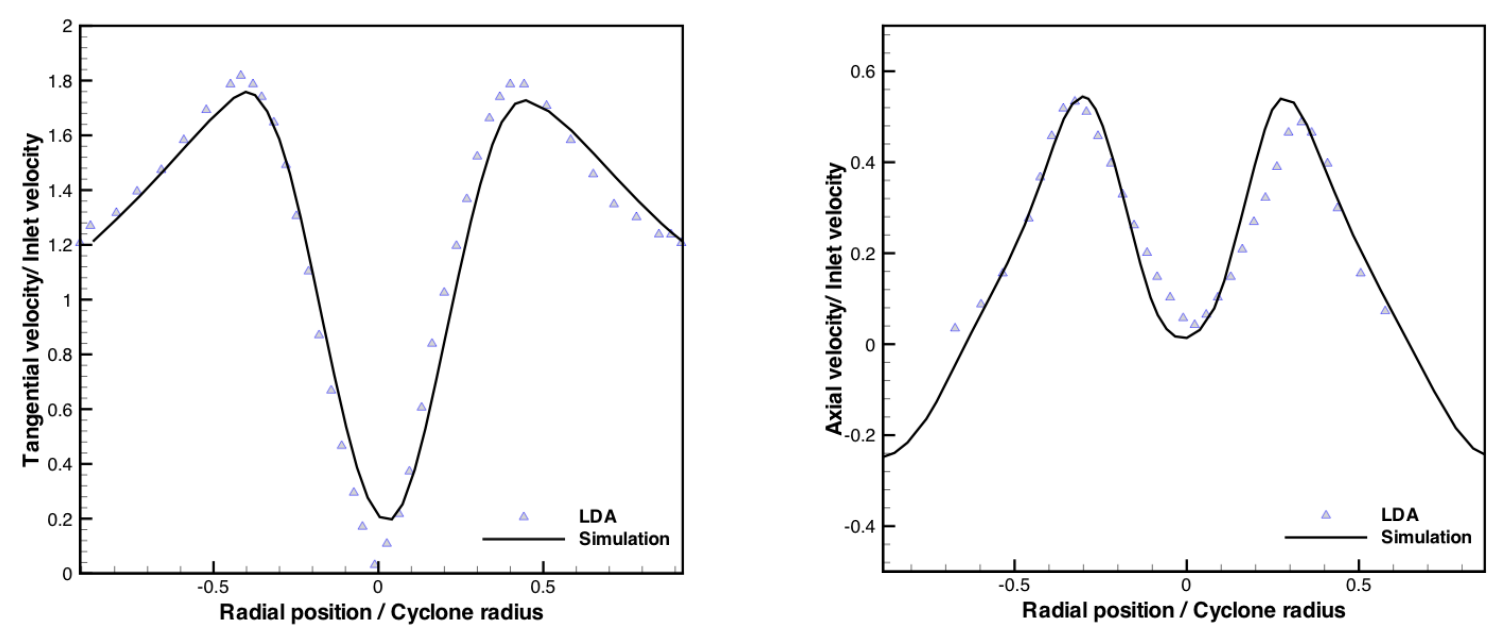

Fig. 2. Comparison of the time averaged tangential and axial velocity between the LDA measurements [21] and the Reynolds stress turbulence model (RSM) results at $94.25 \mathrm{~cm}$ from the cyclone bottom. From left to right tangential and axial velocity, $D_{x} / D=0.5, D=29 \mathrm{~cm}$, The inlet velocity $=10 \mathrm{~m} / \mathrm{s}$. 
C1 (B2)

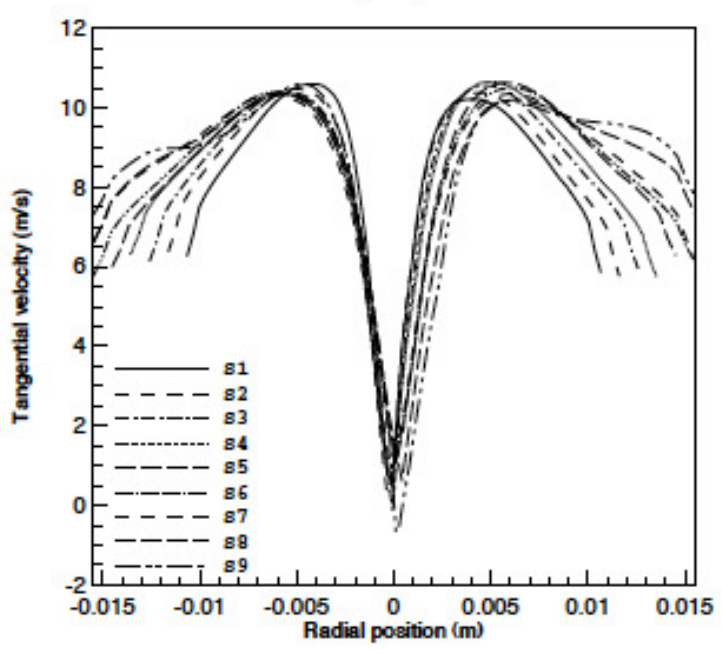

$\mathrm{C} 2$

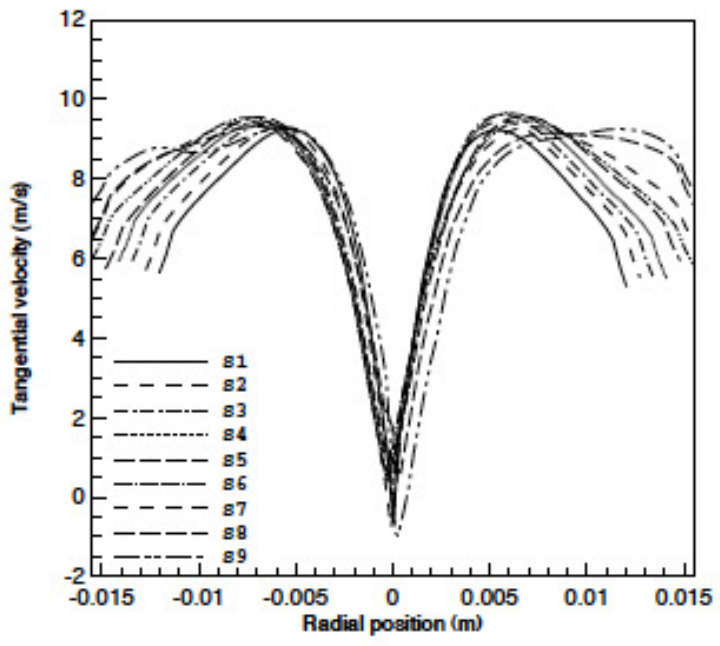

C3

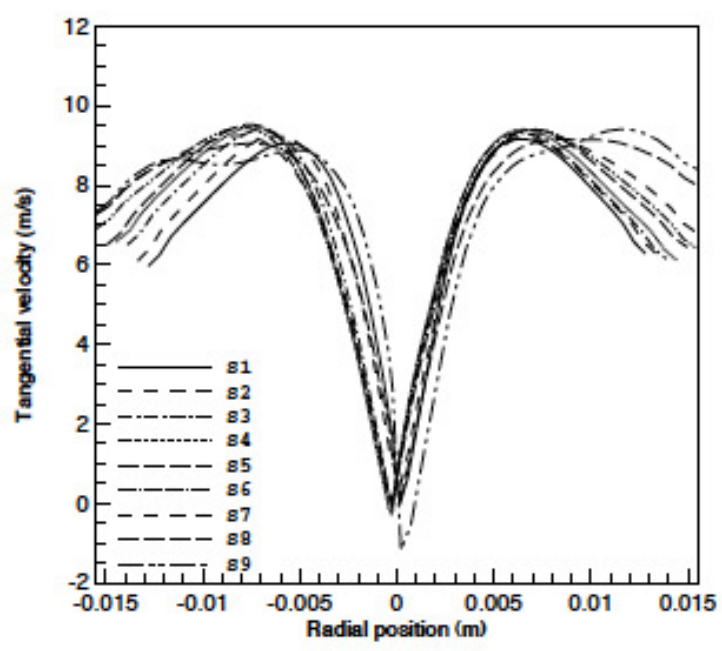

B1

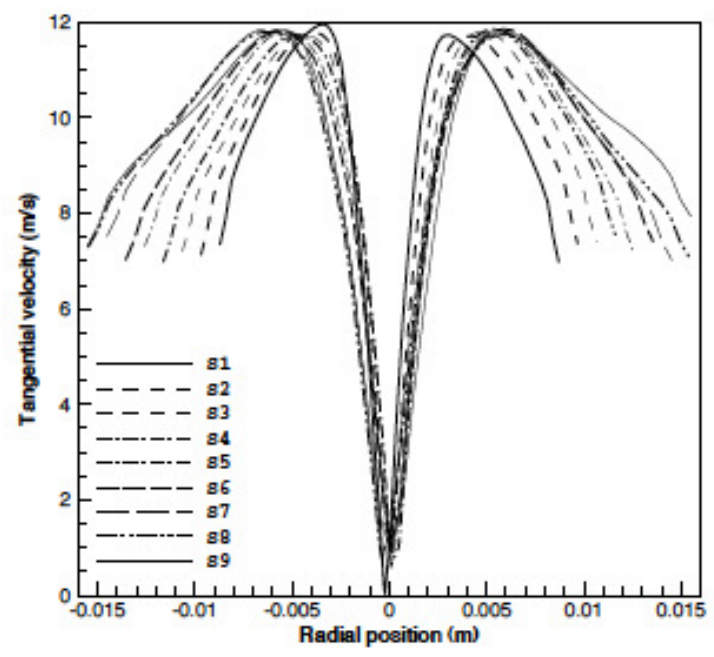

B3

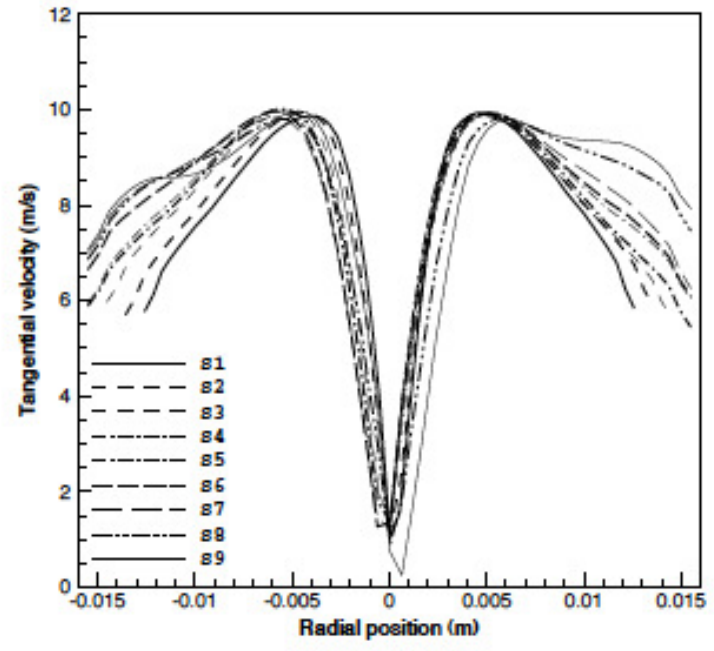

B4

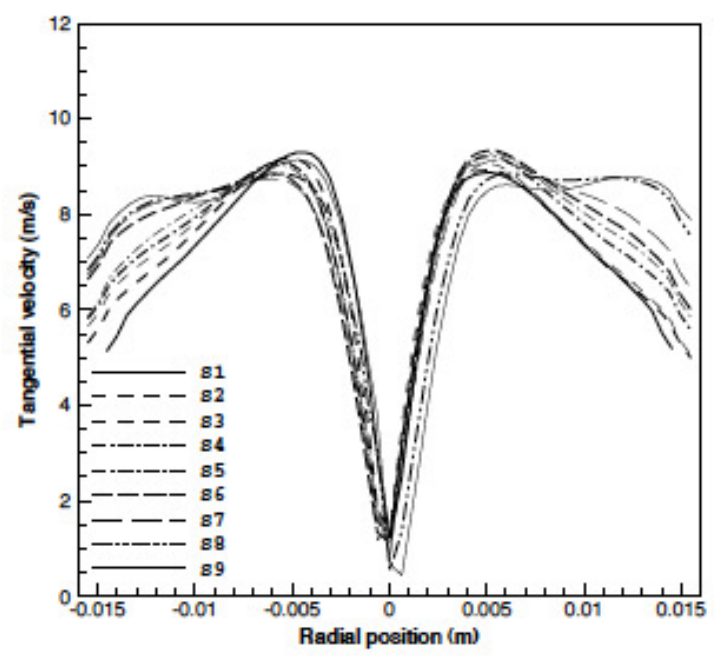

Fig. 3. The radial profile for the time-averaged tangential velocity at different sections. (Note $\mathrm{C} 1=\mathrm{B} 2$ ). 
C1 (B2)

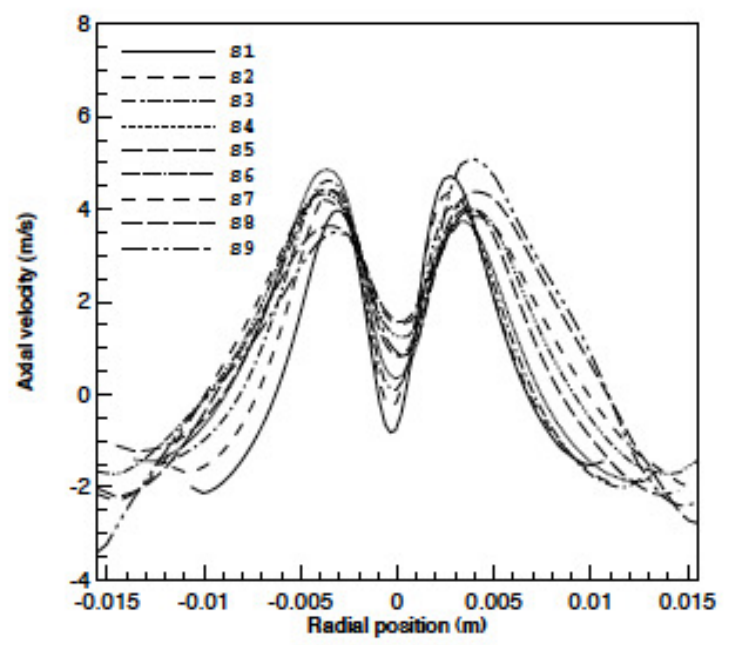

C2

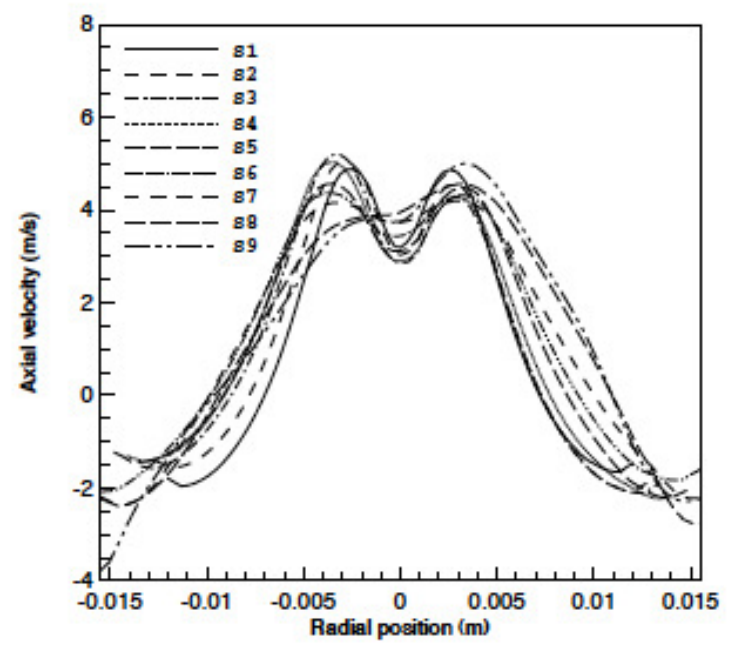

C3

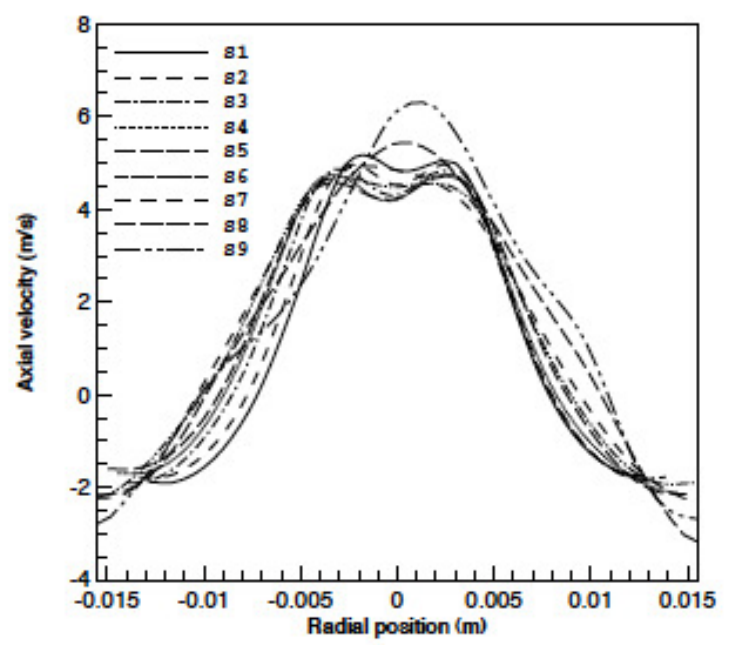

B1

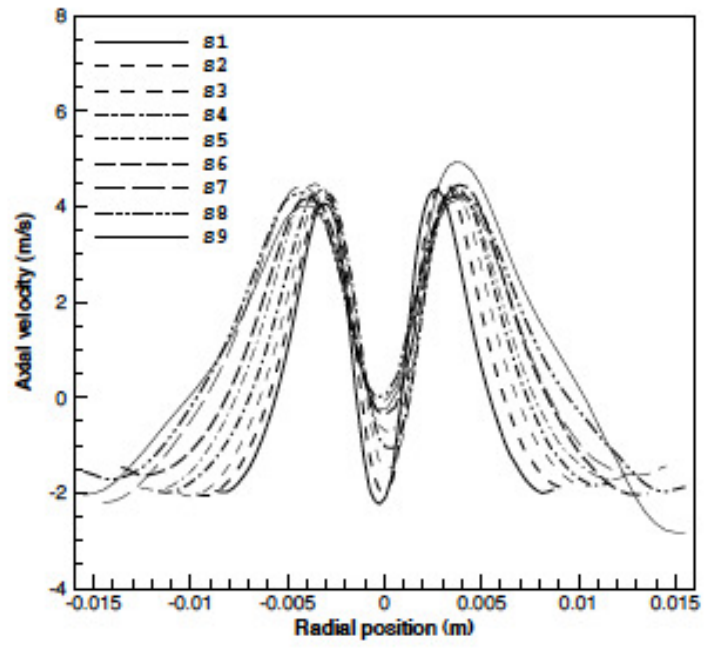

B3

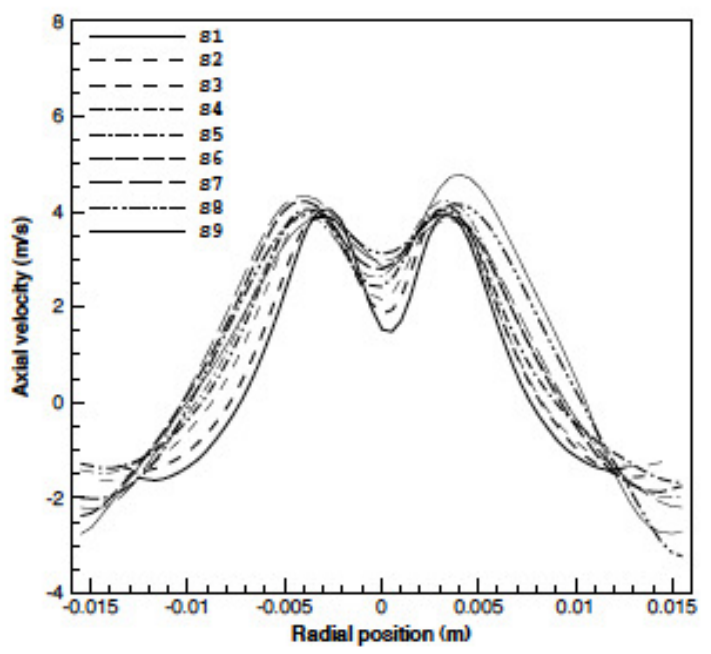

B4

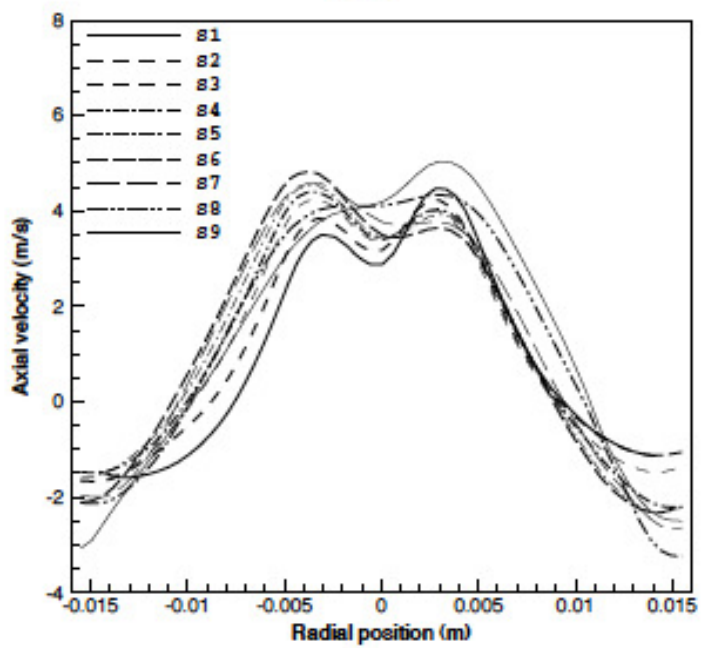

Fig. 4. The radial profile for the time-averaged axial velocity at different sections. (Note $\mathrm{C} 1=\mathrm{B} 2$ ). 
C1 (B2)

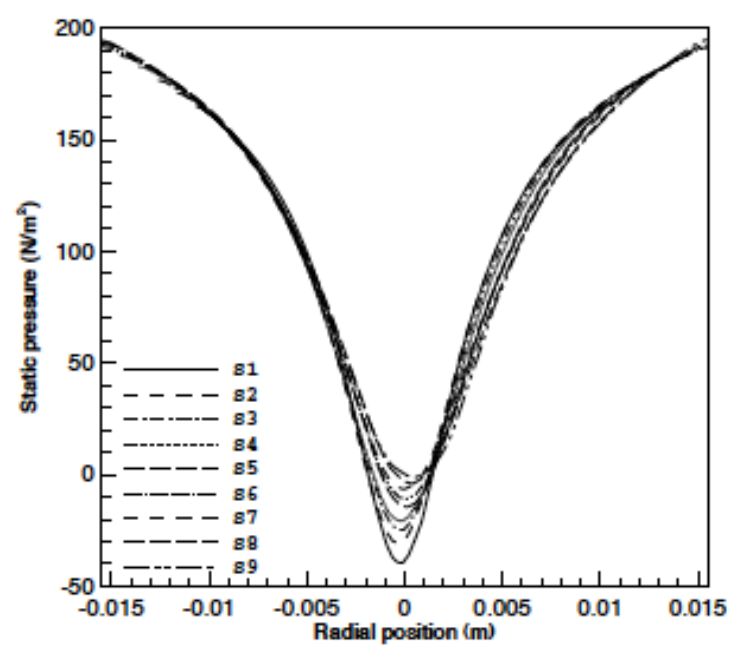

$\mathrm{C} 2$

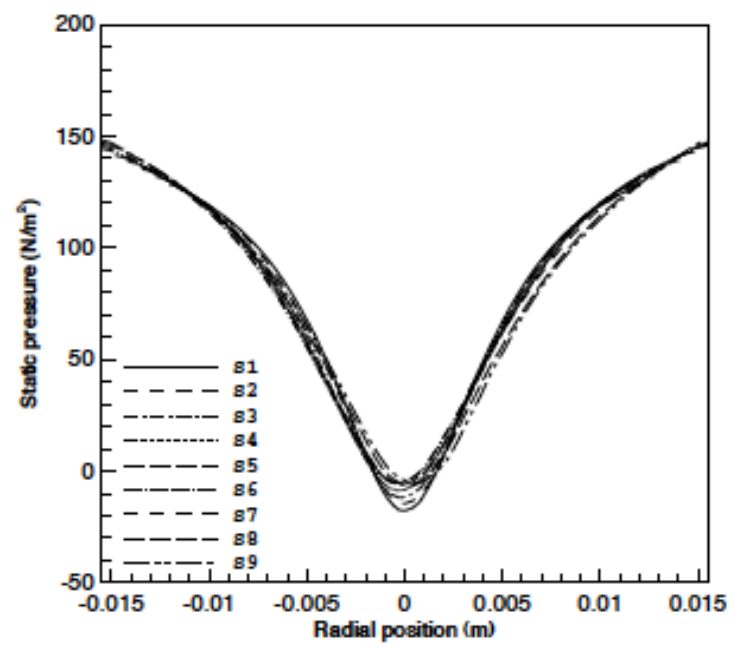

C3

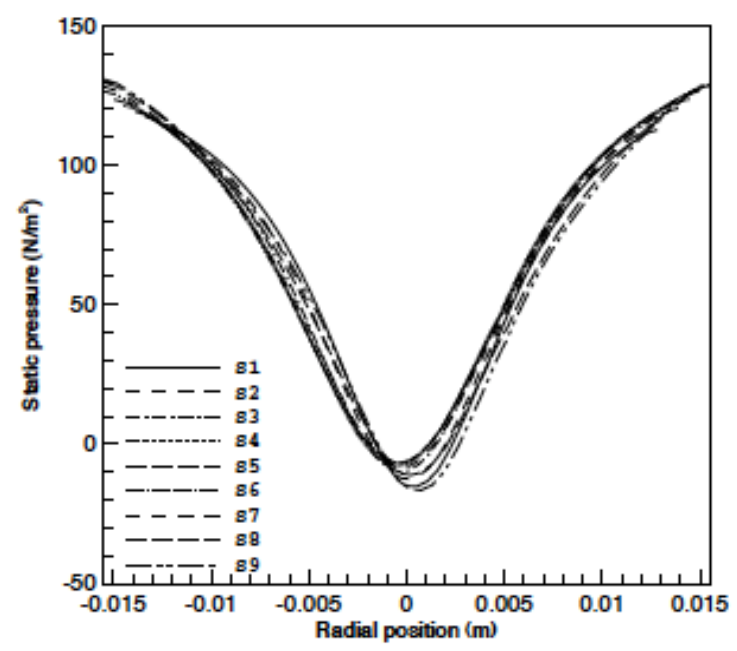

B1

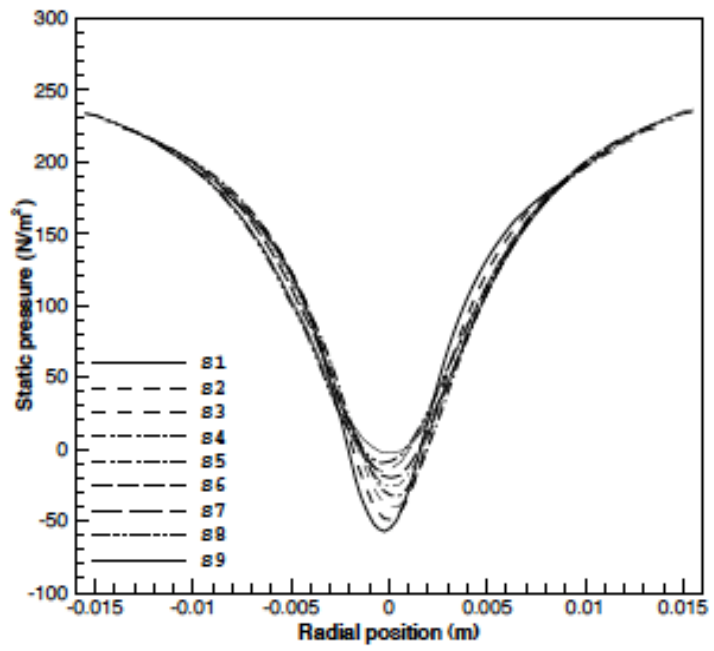

B3

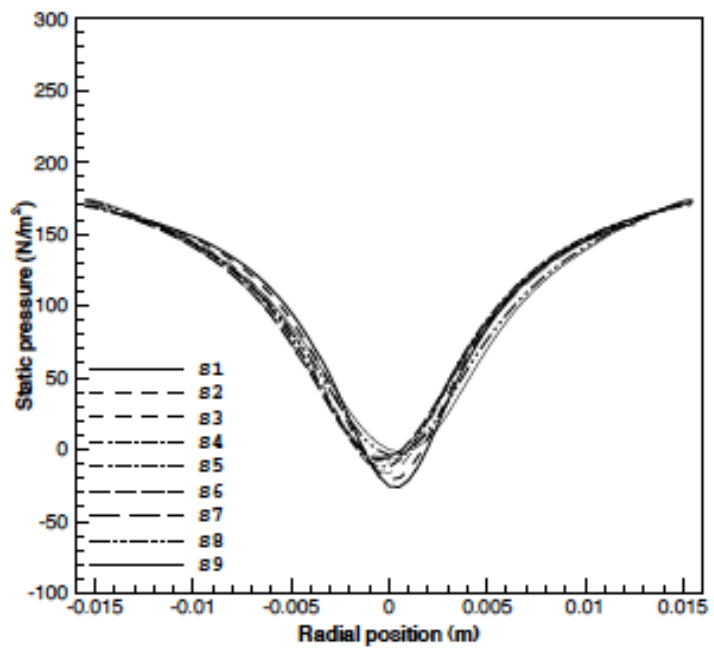

B4

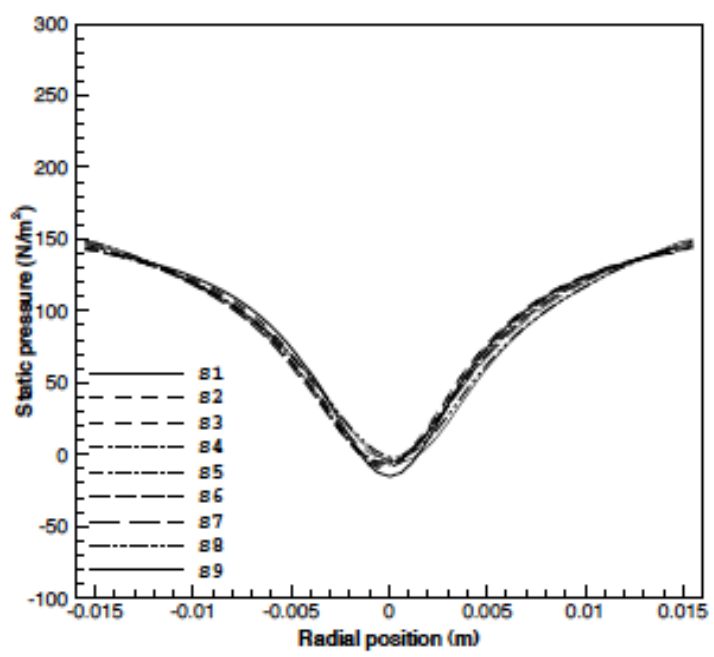

Fig. 5. The radial profile for the time-averaged static pressure at different sections. (Note $\mathrm{C} 1=\mathrm{B} 2$ ). 

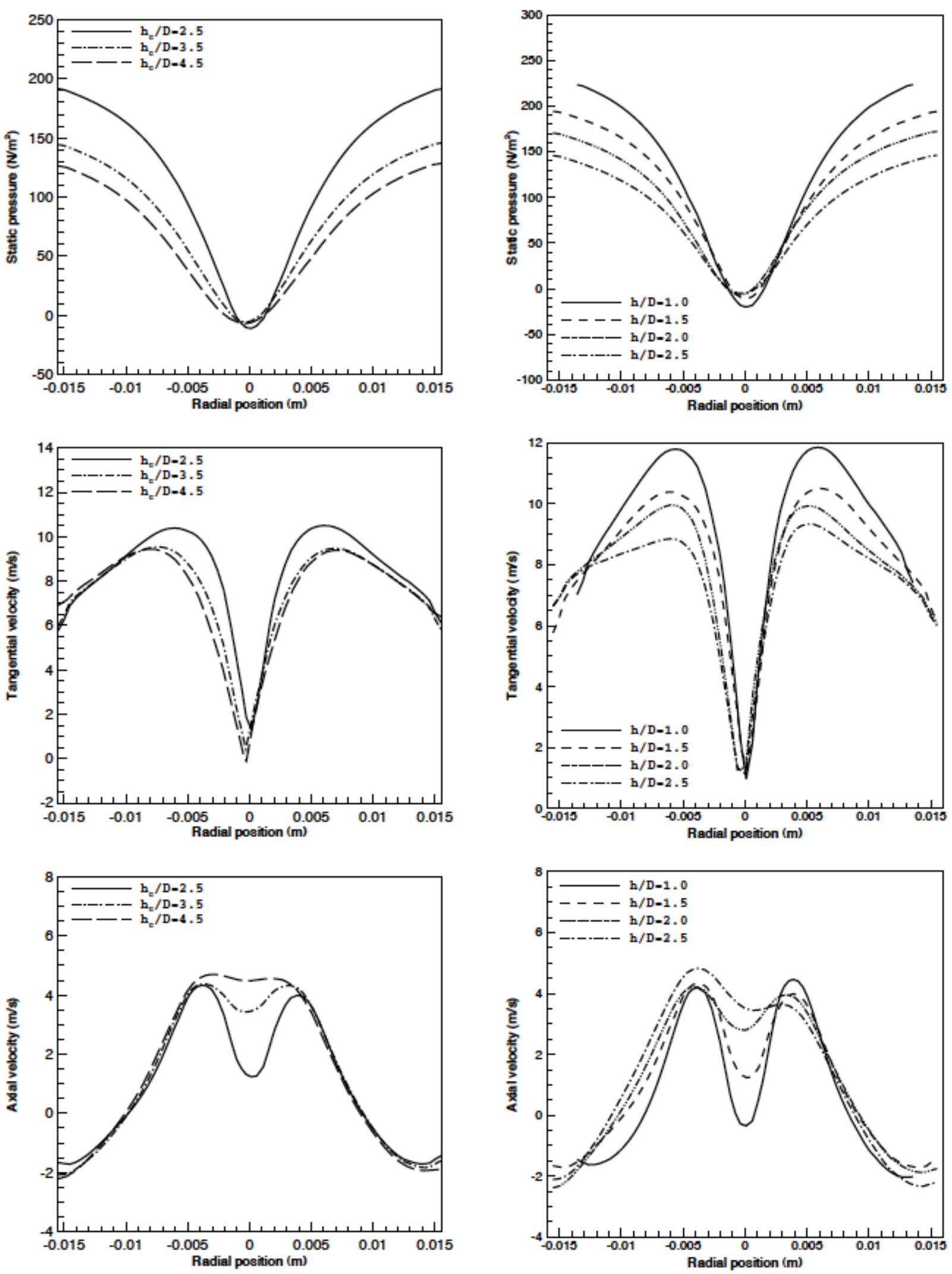

Fig. 6. Comparison between the radial profiles for the time averaged static pressure, tangential and axial velocity at section S6. From top to bottom: static pressure, tangential and axial velocity for different cone heights and barrel heights. 

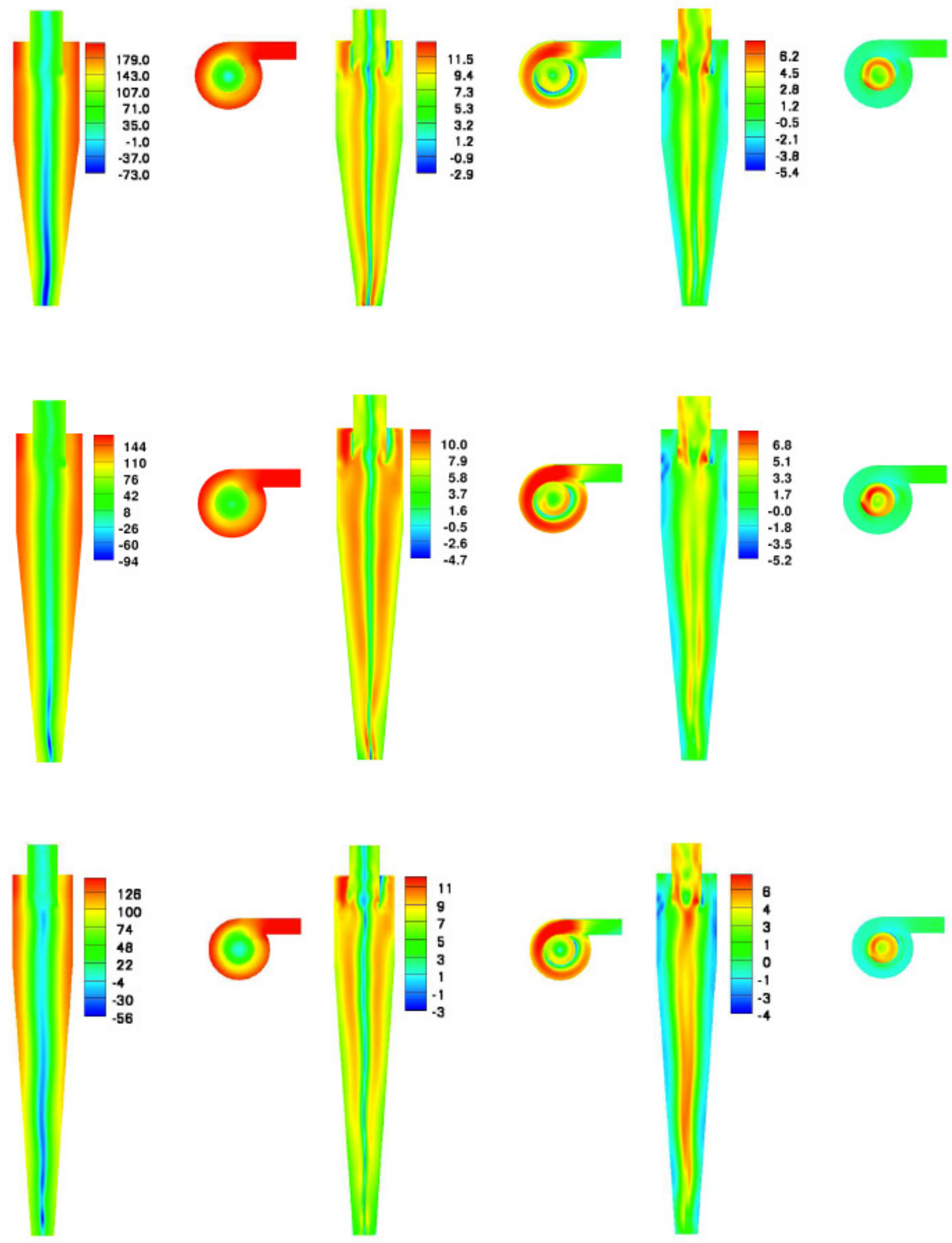

Fig. 7. The contour plots for the time averaged flow variables at sections $Y=0$ (Fig. 1(a)) and throughout the inlet section. From left to right: the static pressure $\left(\mathrm{N} / \mathrm{m}^{2}\right)$, the tangential velocity $(\mathrm{m} / \mathrm{s})$ and the axial velocity $(\mathrm{m} / \mathrm{s})$. From top to bottom cyclone C1-C3. 

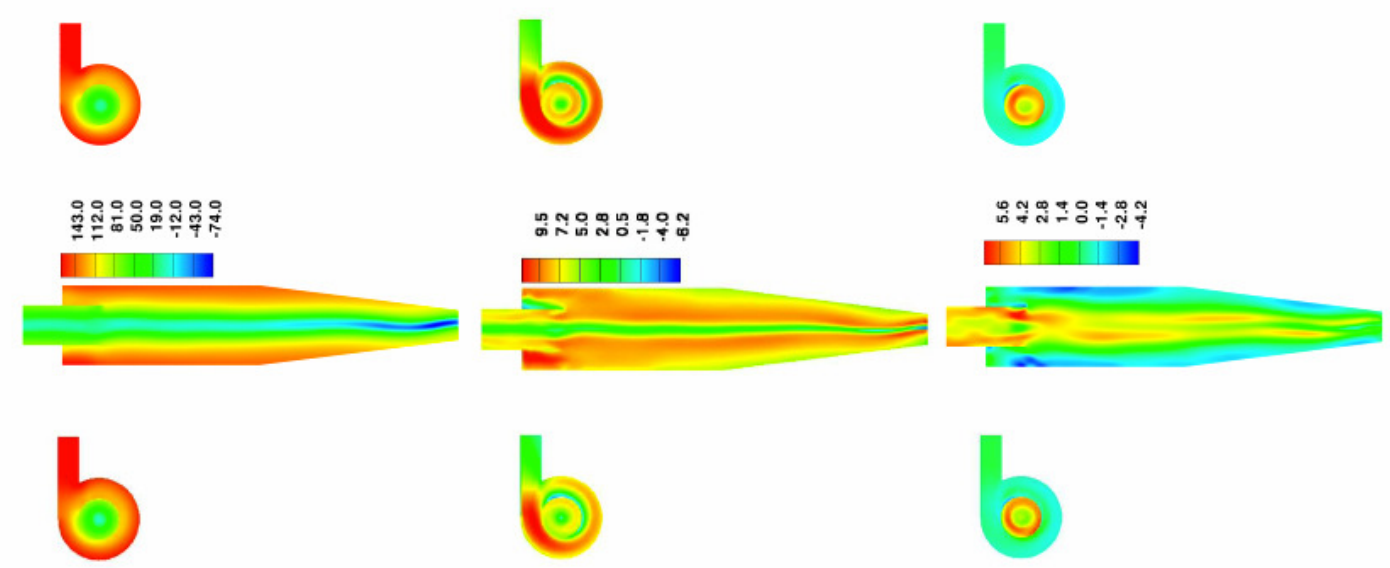

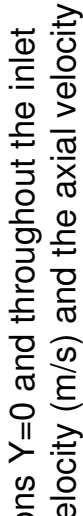
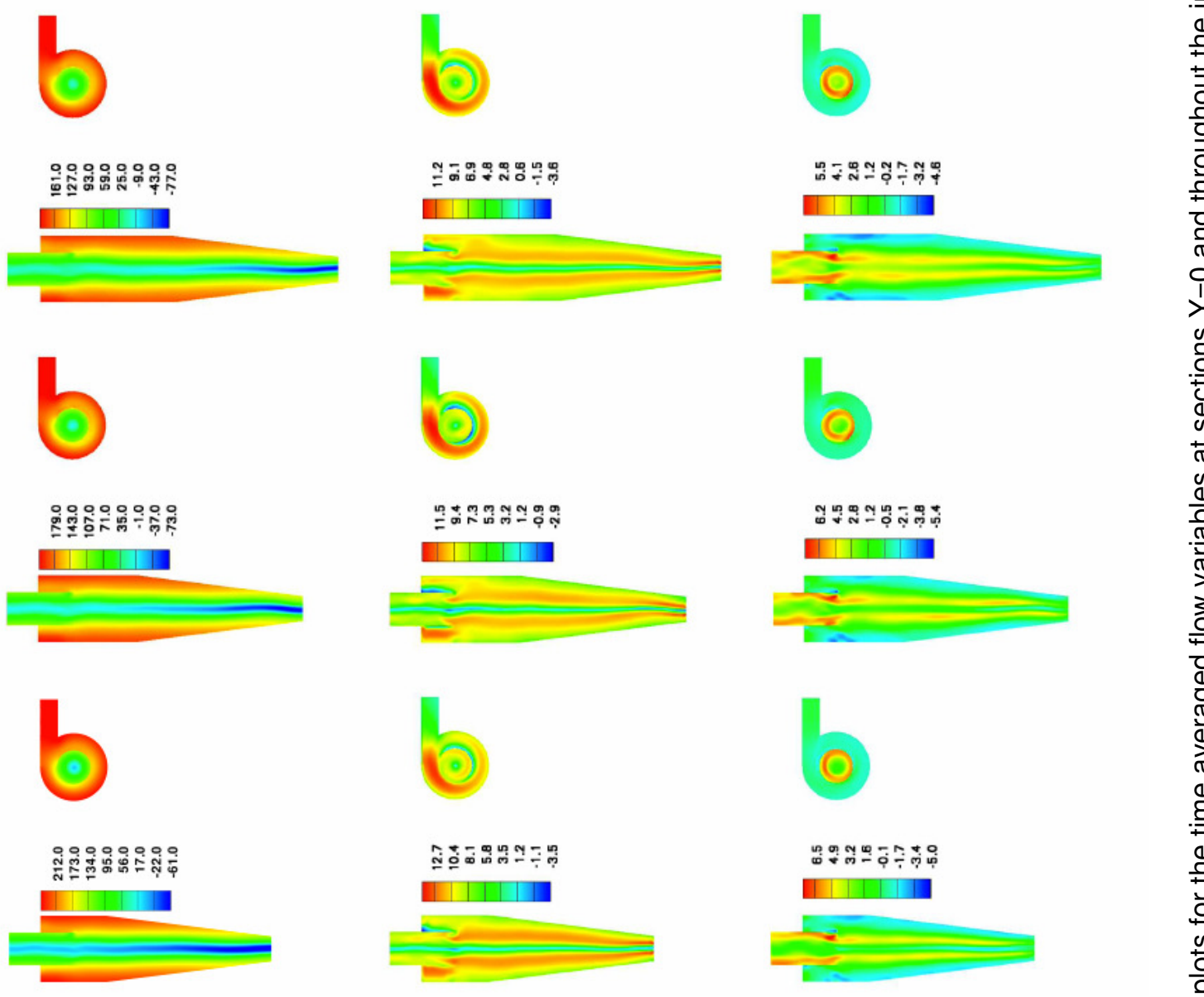

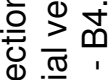

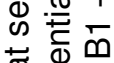

is

응 응 응

西 要

需

$3^{n-\frac{1}{2}}$

는?

焉恋

तू

के

ส한

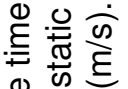

要

$\stackrel{0}{ \pm}$

흘

क

응 훙

훙응

응 응

ญ

둔

$\infty \dot{c}$

ㅎํ 을 


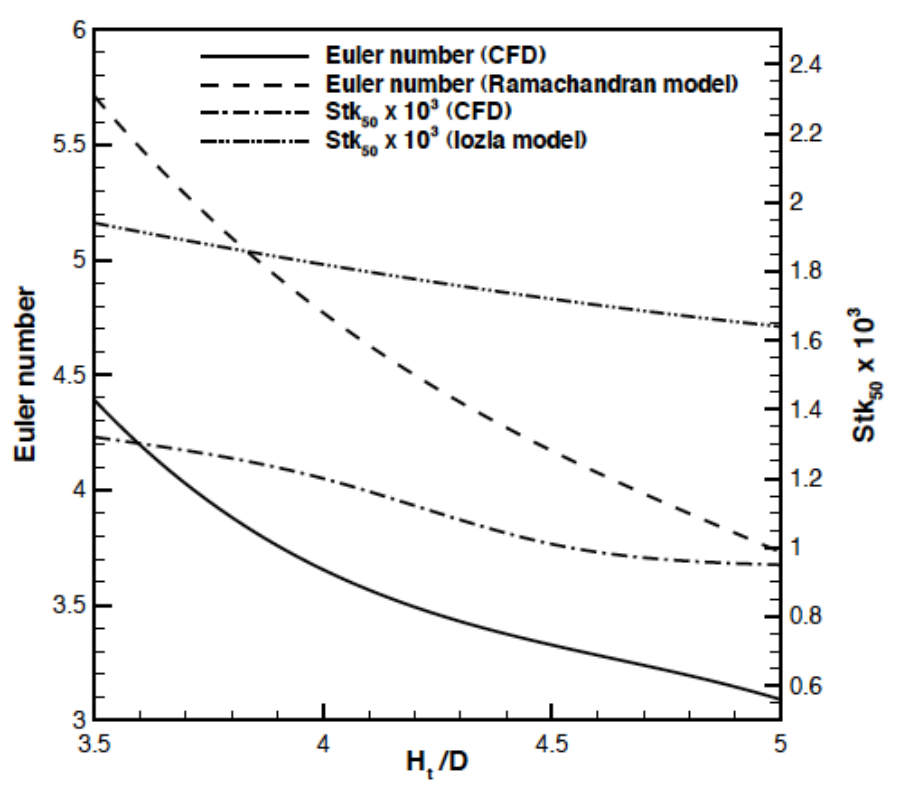

Fig. 9. The effect of barrel height on the Euler number and the Stokes number.

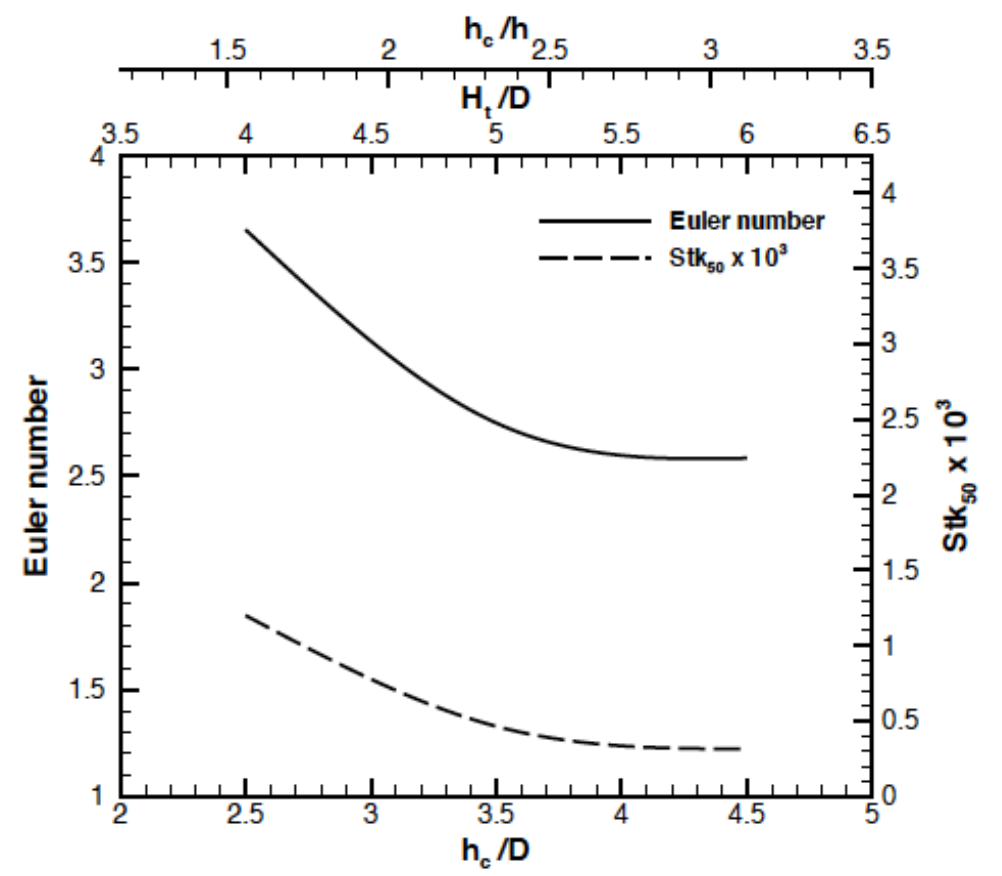

Fig. 10. The effect of cone height on the Euler number and the Stokes number. 


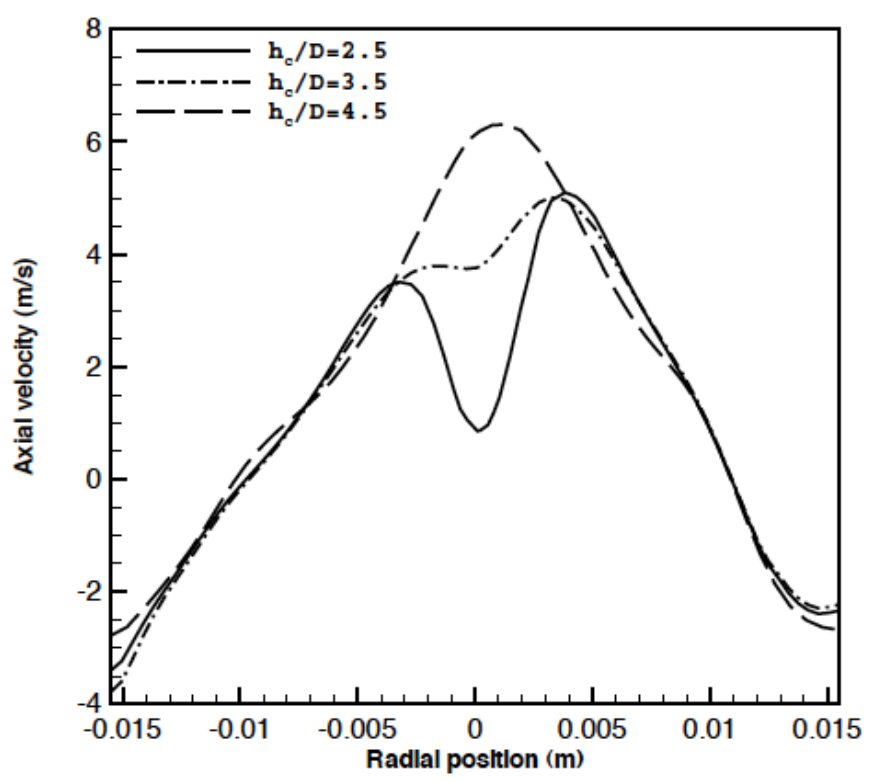

Fig. 11. Comparison between the radial profiles for the time averaged static pressure, tangential and axial velocity at section $\mathrm{S} 9$ for different cone heights.
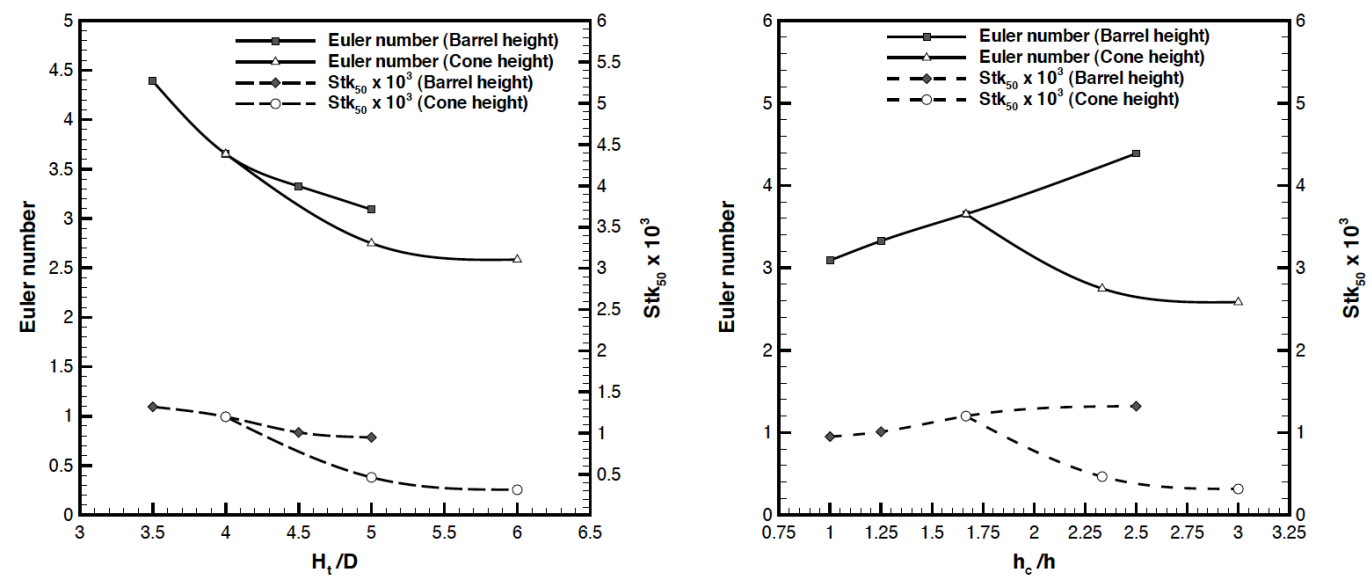

Fig. 12. The variation of the Euler number and the Stokes number with the barrel and cone height. 

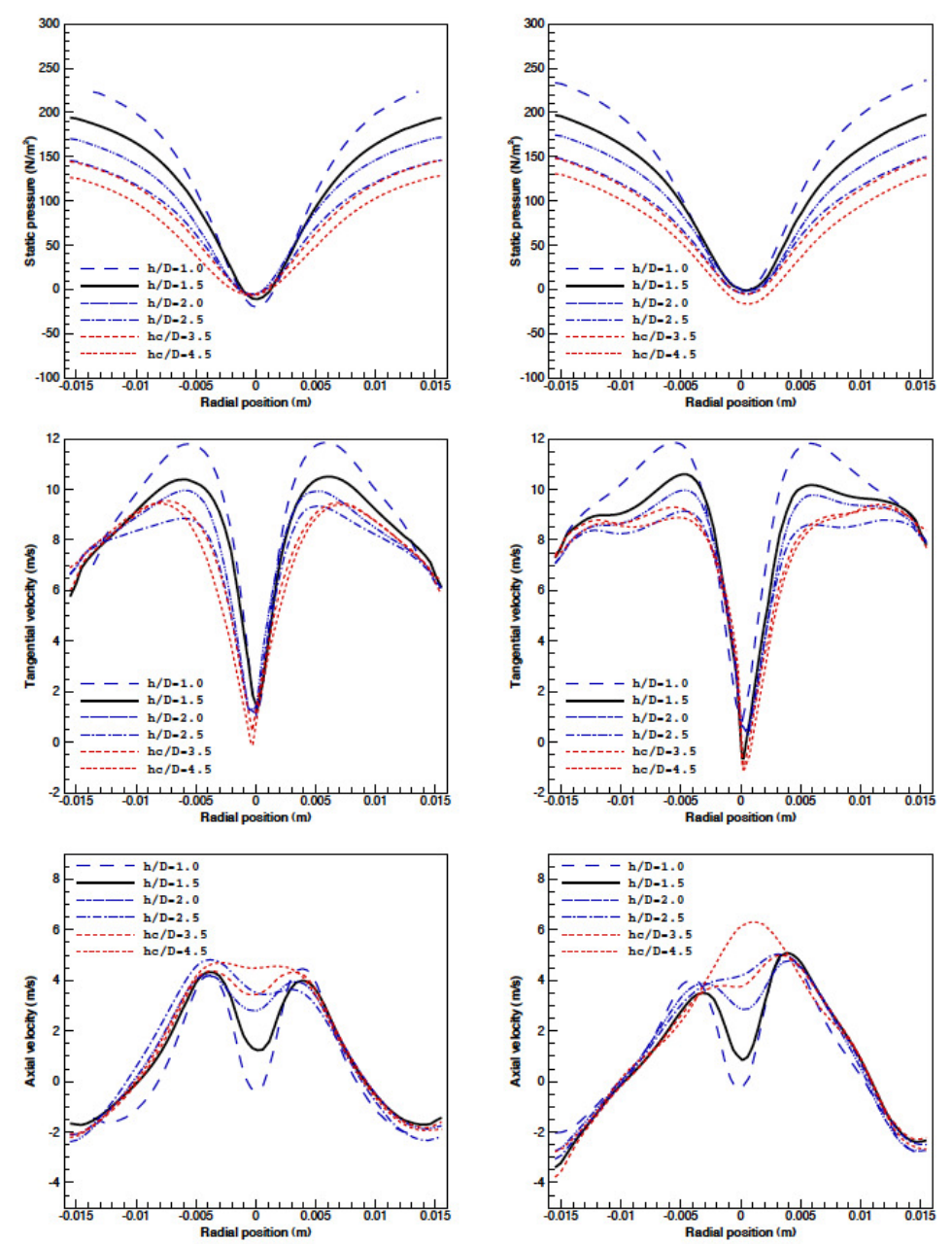

Fig. 13. The radial profile for the time averaged static pressure, tangential and axial velocity at two different sections for the six cyclones. From top to bottom: static pressure, tangential and axial velocity. From left to right: S6 - S9. Note: $h / D=1.5$ also represents $h_{d} / D=2.5$ 